\title{
Isolation and characterization of spliceostatin B, a new analogue of FR901464, from Pseudomonas sp. No. 2663
}

\author{
Xiangyang Liu ${ }^{1,2}$, Sreya Biswas ${ }^{1}$, Gong-Li Tang ${ }^{3}$ and Yi-Qiang Cheng ${ }^{1,2}$ \\ The Journal of Antibiotics (2013) 66, 555-558; doi:10.1038/ja.2013.38; published online 8 May 2013
}

Keywords: cytotoxicity; FR901464; Pseudomonas sp. No. 2663; spliceostatin B

FR901464 (Figure 1), a prototype pre-mRNA splicing inhibitor isolated from the culture broth of Pseudomonas sp. No. 2663, is a potent but unstable cytotoxic compound. ${ }^{1-4}$ Spliceostatin A (Figure 1) is a methylated and more stable derivative of FR901464, shown to bind noncovalently to the splicing factor $3 \mathrm{~b}$ subcomplex of the U2 small nuclear ribonucleoprotein particle of mammalian spliceosome, thus inhibiting pre-mRNA splicing and causing premRNA leakage to the cytoplasm. ${ }^{5,6}$ Recently we discovered thailanstatins A, B and C as three new and significantly more stable natural analogs of FR901464 from the culture broth of Burkholderia thailandensis MSMB43. ${ }^{7}$ For evaluations of the stability, pre-mRNA splicing inhibitory activity and cytotoxicity of thailanstatins, we used FR901464 as a reference compound, which was freshly purified from the Pseudomonas sp. No. 2663 fermentation. During this purification optimization process, another analogous compound of FR901464, named spliceostatin B (1), was discovered. Herein we report the fermentation, isolation, chemical characterization and cytotoxicity of this new natural product.

The FR901464-producing strain Pseudomonas sp. No. $2663^{2}$ was purchased from the National Institute of Bioscience and HumanTechnology, Agency of Industrial Science and Technology, Japan. It was routinely activated from a glycerol stock on Luria-Bertani (LB) agar at $30^{\circ} \mathrm{C}$ for 2 days as a starting plate. Several colonies from the plate were inoculated into a flask containing $250 \mathrm{ml}$ of LB medium and incubated at $30{ }^{\circ} \mathrm{C}$ for $24 \mathrm{~h}$ on a rotary shaker $(150$ r.p.m.) to prepare a seed culture. For fermentation, the seed culture was inoculated at $2 \%(v / v)$ to each of the two fermentors (BioFlo IV, 201 total volume, New Brunswick Scientific, Enfield, CT, USA); each contains 121 of production medium consisting of soluble starch $1 \%$, glycerin $1 \%$, defatted soybean meal $1 \%$, glucose $0.5 \%$, corn steep liquor $0.5 \%,\left(\mathrm{NH}_{4}\right)_{2} \mathrm{SO}_{4} 0.2 \%, \mathrm{CaCO}_{3} 0.2 \%, \mathrm{MgSO}_{4} \cdot 7 \mathrm{H}_{2} \mathrm{O} 0.006 \%$ and antifoam-204 $0.01 \%(\mathrm{pH} 7.0$ ), slightly modified from the literature. $^{2}$ The $\mathrm{pH}$ of bacterial culture was automatically maintained by the fermentor with $1 \mathrm{~N} \mathrm{HCl}$ or $1 \mathrm{~N} \mathrm{NaOH}$, and the fermentation was proceeded at $25^{\circ} \mathrm{C}$ for $48 \mathrm{~h}$ with an agitation of 200 r.p.m. and an air flow-rate of $41 \mathrm{~min}^{-1}$. The repeated fermentation with two fermentors led to an accumulation of 721 of fermentation broth.

Fermentation broth was extracted three times with ethyl acetate $(3: 2, v / v)$, and the extracts were pooled and concentrated to dryness with a rotary evaporator at $35^{\circ} \mathrm{C}$. The resulting crude extract $(25.2 \mathrm{~g})$ was subjected to two steps of silica gel chromatography and one step of octadecyl-silica $\mathrm{C}_{18}$ chromatography on an YFLC AI-580 flash chromatography system (Yamazen, San Bruno, CA, USA), with elution monitored at UV $235 \mathrm{~nm}$ (see Supplementary Information: Scheme S1). In the first step, each $5 \mathrm{~g}$ of crude extract was suspended in $25 \mathrm{ml}$ of ethyl acetate and mixed with $30 \mathrm{~g}$ of silica gel and packed into an injection column $(3.0 \times 12.5 \mathrm{~cm}$, Catalog No. W830 silica gel, Yamazen), which was mounted atop a silica gel Universal Column $(4.8 \times 18.5 \mathrm{~cm}, 200 \mathrm{~g}$ silica gel, $40 \mu \mathrm{m}, 60 \AA)$. The column system was sequentially eluted by 1.11 of each of the following solvents: hexane, hexane:ethyl acetate $(3: 1, v / v)$; hexane:ethyl acetate $(1: 1, v / v)$; ethyl acetate, ethyl acetate:acetone $(1: 1, v / v)$; and acetone, all at a flow rate of $50 \mathrm{ml} \mathrm{min}^{-1}$. The ethyl acetate fraction containing 1 was concentrated to dryness at $35^{\circ} \mathrm{C}$. In the second step, the above resulting residue was suspended in $15 \mathrm{ml}$ of acetone, mixed with $15 \mathrm{~g}$ of silica gel and packed into an injection column $(2.0 \times 6.5 \mathrm{~cm}, 14 \mathrm{~g}$ silica gel $)$, which was mounted atop a silica gel Universal Column $(2.6 \times 12.0 \mathrm{~cm}, 40 \mathrm{~g}$ silica gel, $40 \mu \mathrm{m}, 60 \AA)$. The column system was sequentially eluted with chloroform, and 1,2, 4 and $10 \%$ of acetone in chloroform, and finally acetone at $18 \mathrm{ml} \mathrm{min}^{-1}$. In the third step, the $1 \%$ acetone fraction containing 1 was again concentrated and further fractionated on an octadecyl-silica $\mathrm{C}_{18}$ column system equipped with an injection column $(2.0 \times 6.5 \mathrm{~cm}, 14 \mathrm{~g}$ gel $)$ and a

${ }^{1}$ Department of Biological Sciences, and Department of Chemistry and Biochemistry, University of Wisconsin-Milwaukee, Milwaukee, WI, USA; ${ }^{2}$ UNT System College of Pharmacy, University of North Texas Health Science Center, Fort Worth, TX, USA and ${ }^{3}$ State Key Laboratory of Bio-organic and Natural Products Chemistry, Shanghai Institute of Organic Chemistry, Chinese Academy of Sciences, Shanghai, China

Correspondence: Professor Dr Y-Q Cheng, Department of Biological Sciences, University of Wisconsin-Milwaukee, PO Box 413, Milwaukee, WI 53201, USA.

E-mail: ycheng@uwm.edu

Received 5 December 2012; revised 14 March 2013; accepted 22 March 2013; published online 8 May 2013 
Universal Column $(2.0 \times 8.0 \mathrm{~cm}, 14 \mathrm{~g}$ gel, $50 \mu \mathrm{m}, 120 \AA)$. After loading the sample, the column system was first eluted with $5 \%$ acetonitrile for $3 \mathrm{~min}$, then by a linear gradient of acetonitrile from 5 to $100 \%$ in $10 \mathrm{~min}$, and finally by $100 \%$ acetonitrile for $14 \mathrm{~min}$, with a flow rate of $20 \mathrm{ml} \mathrm{min}^{-1}$. The fraction containing 1 was eluted at $15.7 \mathrm{~min}$. In the final purification step, acetonitrile solution of 1 was purified with a Varian ProStar HPLC system (210 binary pump and 330 photodiode array detector, Varian, Palo Alto, CA, USA) equipped with an Agilent Prep-C18 column $(21.2 \times 250 \mathrm{~mm}, 10 \mu \mathrm{m}$, Agilent, Santa Clara, CA, USA) to give $28 \mathrm{mg}$ of pure 1. As shown in Supplementary Figure S1, 1 was present in significant amount in the culture grown in fermentor but barely in that grown in shaking flask, suggesting that production of 1 is heavily culture conditiondependent.

The structure of 1 (Figure 1) was determined using a combination of UV, IR, HR-MS and NMR spectroscopic analyses (Supplementary Figures S2-S14) and was found to be a new compound after a SciFinder database search.

1 was obtained as a white powder and its physicochemical properties are summarized in Table 1. The IR spectra indicate the presence of hydroxyl $\left(3355 \mathrm{~cm}^{-1}\right)$, carboxyl $\left(2978\right.$ and $\left.2938 \mathrm{~cm}^{-1}\right)$, carbonyl $\left(1735 \mathrm{~cm}^{-1}\right)$, amide carbonyl $\left(1667 \mathrm{~cm}^{-1}\right)$ and conjugated diene moieties $\left(1635 \mathrm{~cm}^{-1}\right)$. HR ESI-MS revealed a quasi-molecular
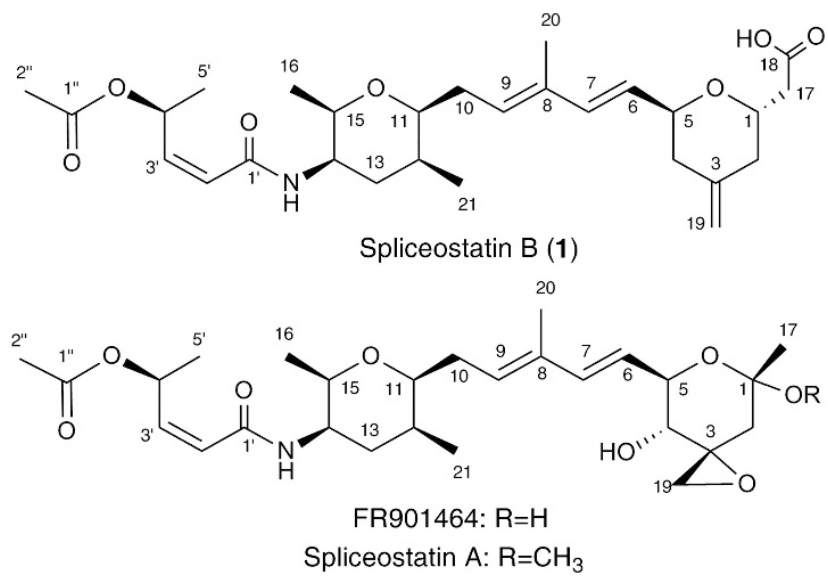

Figure 1 Structures of 1, FR901464 and spliceostatin A.

Table 1 Physicochemical properties of 1

\begin{tabular}{|c|c|}
\hline Appearance & White amorphous powder \\
\hline $\begin{array}{l}\text { Elemental composition reported } \\
\text { by } \mathrm{HR} \text { ESI-MS }[\mathrm{M}+\mathrm{H}]^{+}\end{array}$ & $\mathrm{C}_{28} \mathrm{H}_{42} \mathrm{NO}_{7}$ \\
\hline HR ESI-MS found & $\begin{array}{l}504.2951[\mathrm{M}+\mathrm{H}]^{+} ; 526.2767[\mathrm{M}+\mathrm{Na}]^{+} ; \\
542.2556[\mathrm{M}+\mathrm{K}]^{+}\end{array}$ \\
\hline Calculated & $504.2955[\mathrm{M}+\mathrm{H}]^{+}$ \\
\hline m.p. $\left({ }^{\circ} \mathrm{C}\right)$ & $77-83$ \\
\hline UV $\lambda_{\max }^{\text {Acetonitrile }}(\mathrm{nm} ; \log \varepsilon)$ & $236(4.0)$ \\
\hline $\mathrm{IR}(\mathrm{KBr}) v_{\max }\left(\mathrm{cm}^{-1}\right)$ & $\begin{array}{l}3355,2978,2938,1735,1667,1635,1526, \\
1371,1317,1244,1166,1121,1051\end{array}$ \\
\hline$[\alpha]_{D}^{25}$ & $+4.0\left(\mathrm{CH}_{2} \mathrm{Cl}_{2}, \mathrm{c} 0.1\right)$ \\
\hline Solubility & $\begin{array}{l}\text { DMSO, acetonitrile, acetone, water, } \\
\mathrm{CHCl}_{3}, \mathrm{CH}_{2} \mathrm{Cl}_{2}\end{array}$ \\
\hline
\end{tabular}

Abbreviation: DMSO, dimethyl sulfoxide. ion peak of $\mathrm{m} / z 504.2951$ for $\mathrm{C}_{28} \mathrm{H}_{42} \mathrm{NO}_{7}[\mathrm{M}+\mathrm{H}]^{+}$(calculated 504.2955) and suggested 503 as the MW and $\mathrm{C}_{28} \mathrm{H}_{41} \mathrm{NO}_{7}$ as the molecular formula.

The ${ }^{1} \mathrm{H}$ and ${ }^{13} \mathrm{C}$ NMR spectra in combination with ${ }^{1} \mathrm{H}-{ }^{13} \mathrm{C}$ HSQC NMR data (Table 2) of 1 exhibited signals of five methyl groups $\left(\mathrm{CH}_{3}-16, \mathrm{CH}_{3}-20, \mathrm{CH}_{3}-21, \mathrm{CH}_{3}-5^{\prime}\right.$ and $\left.\mathrm{CH}_{3}-2^{\prime \prime}\right)$, six methylene groups $\left(\mathrm{CH}_{2}-2, \mathrm{CH}_{2}-4, \mathrm{CH}_{2}-10, \mathrm{CH}_{2}-13, \mathrm{CH}_{2}-17\right.$ and $\left.\mathrm{CH}_{2}-19\right)$ and 12 methine group (CH-1, CH-5, CH-11, CH-12, CH-14, CH-15, $\mathrm{CH}-6, \mathrm{CH}-7, \mathrm{CH}-9, \mathrm{CH}-2^{\prime}, \mathrm{CH}-3^{\prime}$ and $\left.\mathrm{CH}-4^{\prime}\right)$, as well as the two quaternary carbons (C-3 and C-8) and three carbonyl carbons (C-18, $\mathrm{C}-1^{\prime}$ and $\left.\mathrm{C}-1^{\prime \prime}\right)$.

The key COSY and HMBC data were shown in Figure 2a. When the ${ }^{1} \mathrm{H}$ and ${ }^{13} \mathrm{C}$ NMR data were compared with those of FR901464, ${ }^{3}$ the spectra showed overall similarities except for the absence of a methyl group and a hydroxyl group at the $\mathrm{C} 1$ and $\mathrm{C} 4$ positions, respectively. On the basis of molecular formula and ${ }^{13} \mathrm{C}$ chemical shifts, 1 has three more chemical shifts, where two $\left(\delta_{C} 38.7\right.$ p.p.m. and $\delta_{C} 174.7$ p.p.m.) are attached to $\mathrm{C} 1$ atom, which was confirmed by the observation of correlations between $1-\mathrm{H}$ and $17-\mathrm{H}$, and $1-\mathrm{H}$ and $2-\mathrm{H}$ (Table 2) in COSY spectrum. Another methylene group ( $\delta_{C} 39.4$ p.p.m. and $\delta_{H} 2.48$ p.p.m., and $\delta_{H} 2.23$ p.p.m.) indicated that this $\mathrm{CH}_{2}$ is free of hydroxyl groups. Comparing with the methylene group ( $\delta_{C} 48.0$ p.p.m.) at C18 position in FR901464, the highly shifted methylene group ( $\delta_{C} 111.4$ p.p.m.) at C19 position indicated that it was a terminal methylene group with a double bond. According to the molecular formula and the already known $\mathrm{NH}$ group, there should be one hydroxyl group in the structure, which was not observable in the ${ }^{1} \mathrm{H}$ NMR spectrum. The presence of such a hydroxyl group in the terminal carboxyl moiety of 1 was confirmed by a positive bromocresol green visualization reaction (yellow spot on dark blue background) on $\mathrm{TLC}^{8}$ (Supplementary Figure S15).

The relative configuration of 1 was determined to be the same as that of FR901464. The geometry of $\mathrm{C} 2^{\prime}$ and C6 double bond was proposed as cis $(Z)$ based on the vicinal coupling constants $J_{\mathrm{H} 2^{\prime}-\mathrm{H} 3^{\prime}}=11.6 \mathrm{~Hz}$ and $J_{\mathrm{H} 6-\mathrm{H} 7}=15.8 \mathrm{~Hz}$ (Table 2). The trans $(E)$ configuration of the double bonds at $\mathrm{C} 8-\mathrm{C} 9$ was indicated by the chemical shift of $\mathrm{C} 20$ at 12.6 p.p.m. (<20 p.p.m.), ${ }^{9}$ and the observations of the NOE correlations between $7-\mathrm{H}$ and $9-\mathrm{H}$ and between $6-\mathrm{H}$ and $20-\mathrm{H}$ (Table 2). Seven of the eight chiral carbons of 1 were assigned according to the related NOE correlations, which were divided into three parts. The configurations of the first part $\mathrm{C} 1 \sim \mathrm{C} 5$ on the first tetrahydropyran ring were shown in Figure $2 \mathrm{~b}$. The cross peaks between $5-\mathrm{H}$ and $17-\mathrm{H}_{2}$ in NOE spectrum suggested a 1,3-diaxial relationship. In the relative stereostructure of the atoms $\mathrm{C} 11 \sim \mathrm{C} 15$ in the second tetrahydropyran ring (Figure $2 \mathrm{~b}$ ), the observation of signals between $15-\mathrm{H}$ and one of the $13-\mathrm{H}_{2}$, and between $15-\mathrm{H}$ and $11-\mathrm{H}$ pointed out the 1, 3-diaxial orientation. The observation of strong NOE correlations between 14$\mathrm{NH}$ and $21-\mathrm{H}_{3}$ suggested a 1, 3-diaxial interaction between $14-\mathrm{NH}$ and $12-\mathrm{CH}_{3}$.

The cytotoxicity of 1 was evaluated in three human cancer cell lines, HCT-116, MDA-MB-235 and H232A, with the MTT method. ${ }^{10}$ 1 exhibited cytotoxic activity against these three cell lines with $\mathrm{GI}_{50}$ (the half-maximum growth inhibitory concentration) values of $1,152 \pm 0.16 \mathrm{~nm}, 916.6 \pm 1.20 \mathrm{~nm}$ and $893.6 \pm 1.64 \mathrm{~nm}$, respectively. FR901464 was reported to have $\mathrm{GI}_{50}$ values of $1.8 \mathrm{~nm}, 1.3 \mathrm{~nm}$, $0.6 \mathrm{~nm}, 1.0 \mathrm{~nm}$ and $3.3 \mathrm{~nm}$ against MCF-7, A549, HCT-116, SW480 and P388 cell lines, respectively. ${ }^{1}$ Apart from potentially differential cytotoxicities against different cell lines, 1 appeared to be a much weaker cytotoxic compound than FR901464. 
Table $2{ }^{13} \mathrm{C}$ and ${ }^{1} \mathrm{H}$ NMR spectroscopic data for $1\left(\mathrm{CDCl}_{3}, 298 \mathrm{~K}\right)$

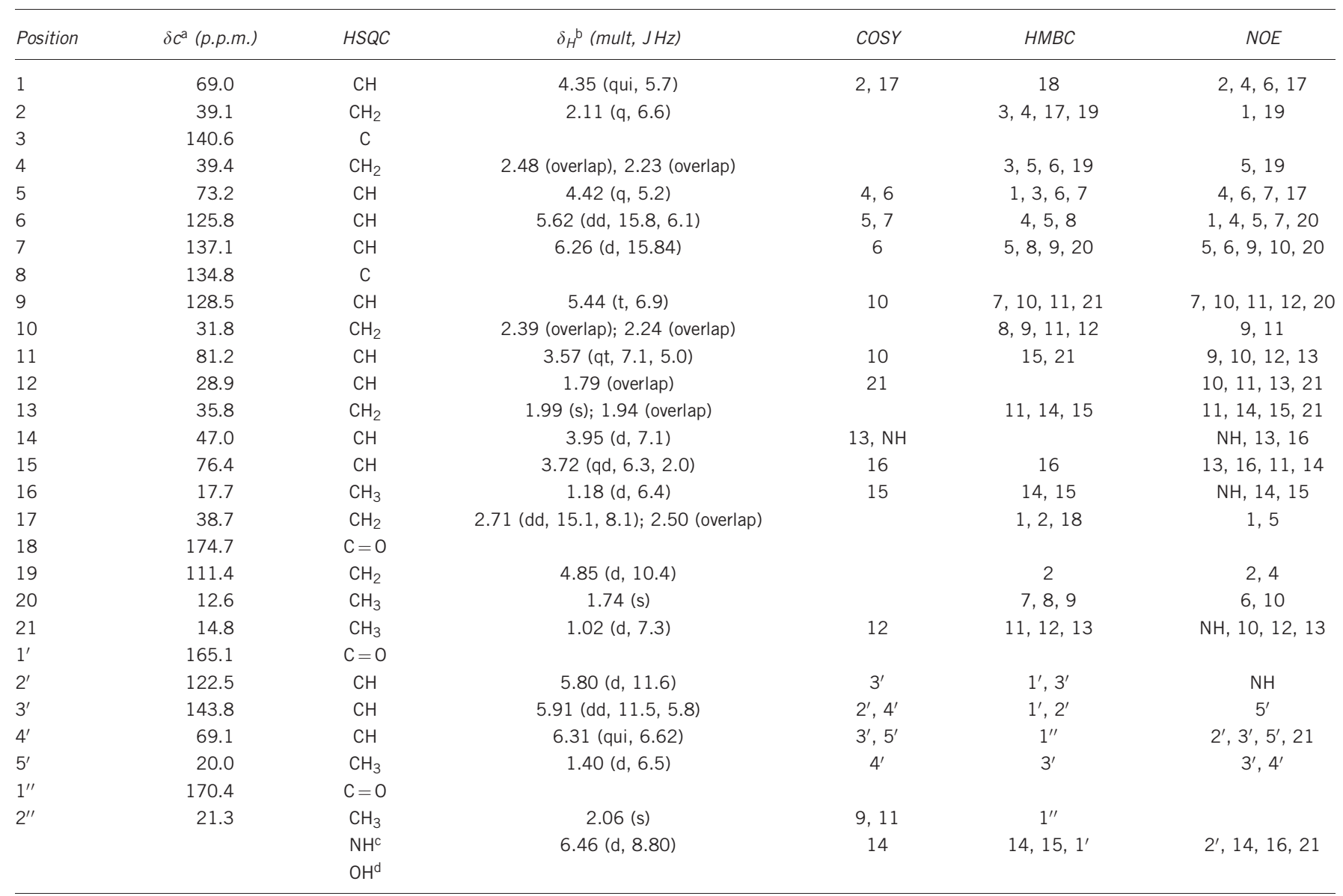

aThe ${ }^{13} \mathrm{C}$ NMR was measured at $125 \mathrm{MHz}$.

a

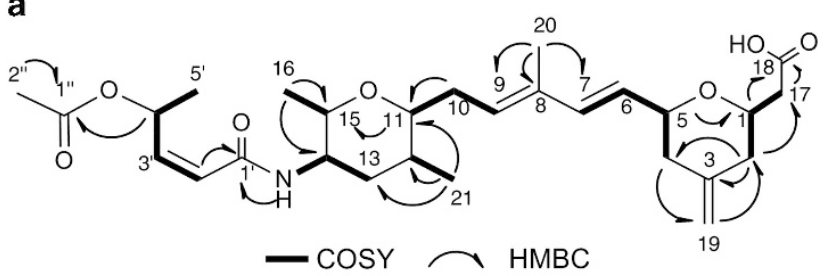

b

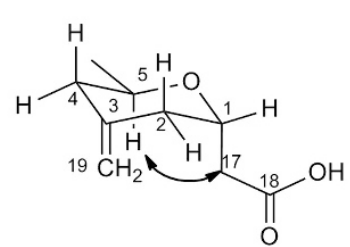

r NOE

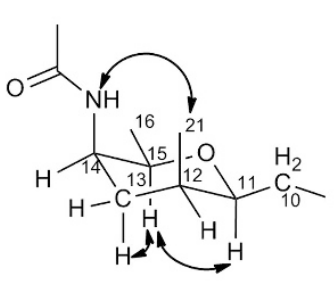

r NOE
Figure 2 Key COSY and HMBC correlations of 1 (a), and key NOE correlations of 1 fragments (b).

1 differs structurally from FR901464 at four points (Figure 1): substitution of an epoxide group at $\mathrm{C} 3$ position with a terminal methylene moiety, presence of a carboxyl moiety at $\mathrm{C} 17$ position, and absence of two hydroxyl groups at $\mathrm{C} 1$ and $\mathrm{C} 4$ positions, respectively. It was reported that a loss of $\mathrm{C} 4$ hydrogen bond donor decreases the cytotoxicity of meayamycin B (a synthetic FR901464 analog) about fourfold. ${ }^{11}$ The importance of the $\mathrm{C} 3$ epoxide moiety for bioactivity has been documented in two independent studies. First, substitution of the C3 epoxide moiety in FR901464 by a terminal methylene group decreases the cytotoxicity about fivefold. ${ }^{5}$ Second, a non-epoxide analog of meayamycin that still contains the oxygen atom at the $\mathrm{C} 3$ position completely lost the activity, with $\mathrm{IC}_{50}$ values changed from $0.02 \mathrm{~nm}$ to $>10000 \mathrm{~nm} .{ }^{11}$ Although there is no concrete evidence about the influence of the carboxyl moiety at $\mathrm{C} 17$ position on the bioactivity of 1 , our studies on thailanstatins suggested that this moiety is critical to compound stability under weak alkaline conditions. ${ }^{7}$ Collectively, the absence of an epoxide moiety at $\mathrm{C} 3$ position and a hydroxyl group at $\mathrm{C} 4$ position of 1 most likely contributes to its weak cytotoxicity, which, in turn, supports the importance of those functionalities in FR901464 class of natural or synthetic compounds.

\section{ACKNOWLEDGEMENTS}

This work was supported in part by a Catalyst Award from the University of Wisconsin-Milwaukee Research Foundation and a grant from the US National Institute of Health (R01 CA152212). 
1 Nakajima, H. et al. New antitumor substances, FR901463, FR901464 and FR901465. II. Activities against experimental tumors in mice and mechanism of action. J. Antibiot. (Tokyo) 49, 1204-1211 (1996).

2 Nakajima, H. et al. New antitumor substances, FR901463, FR901464 and FR901465. I. Taxonomy, fermentation, isolation, physico-chemical properties and biological activities. J. Antibiot. (Tokyo) 49, 1196-1203 (1996).

3 Nakajima, H., Takase, S., Terano, H. \& Tanaka, H. New antitumor substances, FR901463, FR901464 and FR901465. III. Structures of FR901463, FR901464 and FR901465. J. Antibiot. (Tokyo) 50, 96-99 (1997).

4 Albert, B. J., Sivaramakrishnan, A., Naka, T., Czaicki, N. L. \& Koide, K. Total syntheses, fragmentation studies, and antitumor/antiproliferative activities of FR901464 and its low picomolar analogue. J. Am. Chem. Soc. 129, 2648-2659 (2007).

5 Motoyoshi, H. et al. Structure-activity relationship for FR901464: a versatile method for the conversion and preparation of biologically active biotinylated probes. Biosci. Biotechnol. Biochem. 68, 2178-2182 (2004).
6 Kaida, D. et al. Spliceostatin A targets SF3b and inhibits both splicing and nuclea retention of pre-mRNA. Nat. Chem. Biol. 3, 576-583 (2007).

7 Liu, X. et al. Genomics-guided discovery of thailanstatins A, B and C as pre-mRNA splicing inhibitors and anti-proliferative agents from Burkholderia thailandensis MSMB43. J. Nat. Prod. doi:10.1021/np300913h (2013).

8 Wardas, W., Lipska, I. \& Bober, K. TLC fractionation and visualization of selected phenolic compounds applied as drugs. Acta. Pol. Pharm. 57, 15-21 (2000).

9 Lange, G. L. \& Lee, M. ${ }^{13} \mathrm{C}$ NMR determination of the configuration of methylsubstituted double bonds in medium- and large-ring terpenoids. Magn. Res. Chem. 24, 656-658 (1986)

10 Mosmann, T. Rapid colorimetric assay for cellular growth and survival: application to proliferation and cytotoxicity assays. J. Immunol. Methods 65, 55-63 (1983).

11 Osman, S. et al. Structural requirements for the antiproliferative activity of pre-mRNA splicing inhibitor FR901464. Chemistry 17, 895-904 (2011).

Supplementary Information accompanies the paper on The Journal of Antibiotics website (http://www.nature.com/ja) 